\title{
KAJIAN PROSES PEMBELAJARAN DALAM PENYULUHAN PERTANIAN UNTUK MENINGKATKAN KOMPETENSI KEWIRAUSAHAAN PETANI JAGUNG DI KABUPATEN GROBOGAN PROVINSI JAWA TENGAH
}

\author{
Yuniar Aviati dan Teguh Endaryanto \\ Jurusan Agribisnis, Fakultas Pertanian Universitas Lampung \\ Jl. Brodjonegoro No 1 Gedung Meneng Bandar Lampung, Kode Pos 35145 \\ Email: yuniarafiati@yahoo.com
}

\begin{abstract}
Corn cultivation requires farmers' human resources (HR) who have entrepreneurial competence, farmers who have mastered the technical knowledge of farming and farming management. A competent farmer makes a creative and innovative farmer as an entrepreneur in agriculture. Agricultural extension as a non-formal education for farmers is a means to improve the entrepreneurial skills of farmers in corn farming. This study uses a qualitative method with observation and participation in farmer group activities. In addition, the focus group discussion (FGD) method is also used to determine the efforts made in improving aspects of learning and entrepreneurial competence. The results of the study found that (1) aspects of the learning process in agricultural extension were extension material, interaction between extension workers and farmers, extension methods and extension evaluation; (2) factors that can increase entrepreneurial competence for corn farmers are farmers' participation in social institutions in the community and government policies on corn commodities.
\end{abstract}

Keywords: Learning, Extension, Farmer Entrepreneurship Competence, Grobogan.

\section{PENDAHULUAN}

Penelitian ini dilatarbelakangi dari hasil penelitian dari Malta (2011) menunjukkan bahwa tingkat kinerja petani jagung termasuk kategori rendah; petani umumnya berumur tua (tidak produktif), pendidikan formal rendah, interaksi dengan penyuluh rendah, keterlibatan dalam kelompok tani termasuk rendah, motivasi petani dalam kelompok tani rendah. Penyuluhan pertanian sebagai bentuk pendidikan nonformal bagi petani dan keluarganya merupakan suatu upaya untuk meningkatkan kompetensi petani (Slamet,
2001; Asngari, 2001 dan Sumardjo, 2012). Mardikanto (2009) menyatakan bahwa kemampuan penyuluh untuk melayani kliennya masih terpusat pada aspek teknis budidaya pertanian, sedang aspek manajemen, pendidikan kewirausahaan, dan hak-hak politik petani relatif tidak tersentuh.

Penelitian ini bertujuan: (1) Mengkaji aspek dalam proses pembelajaran yang memberikan pengaruh terhadap kompetesi kewirausahaan petani jagung; (2) Mengkaji faktor-faktor yang memperngaruhi kompetensi kewirausahaan petani jagung. 


\section{METODE PENELITIAN}

Penelitian ini dilakukan pada bulan Mei 2018 sampai dengan bulan September 2018 di wilayah Kabupaten Grobogan pada kabupaten sentra produksi jagung yaitu Kabupaten Grobogan. Jenis Penelitian adalah penelitian kualitatif. Untuk menjawab tujuan pertama digunakan analisis desktiptif dan digunakan Focus Group Discussion (FGD) untuk menggali informasi dari anggota kelompok tani sebagai informan pada penelitian ini.

\section{HASIL DAN PEMBAHASAN}

Persepsi Petani terhadap Aspek Proses Pembelajaran dalam Penyuluhan

Materi penyuluhan merupakan inti dari suatu proses pembelajaran yang akan diterima oleh sasaran, materi penyuluhan yang telah diterima oleh informan meliputi teknologi dalam budidaya jagung seperti: pengolahan lahan, pemberantasan hama penyakit, penangan pascapanen. Menurut informan materi penyuluhan yang diperlukan oleh mereka meliputi bagaimana mengetahui kualitas jagung yang memenuhi standar pabrik pakan ternak, membangun jaringan pasar langsung dengan pabrikan dengan tanpa melalui perantara/cakil sehingga petani bisa mendapatkan harga yang sesuai kualitas jagung dengan tanpa dimainkan di tingkat perantara. Informan berpendapat bahwa materi penyuluhan tidak hanya berkaitan dengan teknis budidaya jagung karena mereka sudah mengetahui dan mengerjakan budidaya jagung rata-rata antara 9-17 tahun sehingga mereka menganggap sudah faham dengan seluk beluk pertumbuhan dan permasalahan jagung. Informan mengharapkan materi penyuluhan lebih diarahkan kepada membangun karakter mereka sebagai seorang pengusaha sehingga mampu mengembangkan usaha jagung mereka.

Interaksi petani dengan penyuluh dalam penelitian ini dikaji melalui (a) jumlah interaksi antara petani dengan penyuluh per musim tanam, (b) tingkat kekompakan diantara petani, (c) petani terlibat aktif dan menyampaikan ide pada kegiatan penyuluhan, (d) petani merasa senang mengikuti kegiatan penyuluhan. Hal ini sesuai dengan pendapat Widoyoko (2012), bahwa interaksi antara pemberi materi dan pembelajar dapat dikaji melalui beberapa indikator antara lain (1) kekompakan diantara para pembelajar, (2) keterlibatan pembelajar dalam kegiatan pembelajaran dan (3) tingkat kepuasan pembelajar dalam mengikuti kegiatan pembelajaran. Selain itu Sudjana (2012) menyatakan bahwa interaksi antara pemberi materi dan warga belajar berkenaan dengan komunikasi atau hubungan timbal balik dua arah antara pemberi materi dan warga belajar dalam melakukan kegiatan pembelajaran. Oleh karena itu selama proses pembelajaran dalam penyuluhan interaksi antara petani dengan penyuluh harus tetap terjalin, terjaga, harmonis dan berkesinambungan agar tujuan pembelajaran dalam penyuluhan dapat tercapai.

Metode penyuluhan merupakan cara-cara penyampaian materi penyuluhan secara 
sistematis sehingga materi penyuluhan dapat dimengerti dan diterima petani sasaran (Ibrahim dkk., 2003). Metode penyuluhan dalam penelitian ini diukur dari penilaian informan terhadap (a) kesesuaian metode dengan materi yang disampaikan, (b) metode penyuluhan yang digunakan sesuai dengan kemampuan petani, (c) kemampuan metode penyuluhan yang digunakan mengaktifkan petani dalam membangun pengetahuan sendiri, (d) metode penyuluhan menumbuhkan motivasi kerja petani untuk berusahatani lebih baik lagi.

Informan berpendapat bahwa metode penyuluhan yang digunakan belum sesuai dengan materi, kemampuan penyuluh juga belum dapat membuat petani termotivasi untuk membangun atau pencari pengetahuan sendiri dan penyuluh belum mampu untuk menggunakan metode penyuluhan yang bervariasi pada setiap kesempatan. Metode penyuluhan yang digunakan terbatas pada penyampaian materi dan tanya jawab dan penyuluh masih menjadi pusat pembelajaran. Metode penyuluhan yang ada saat ini belum menggunakan metode partisipatif seperti simulasi atau permainan peran untuk membangkitkan motivasi kerja petani sehingga petani menjadi bagian dari penyuluhan tersebut dan meningkatkan partisipasi petani.

Oleh karena itu untuk mencapai keberhasilan suatu penyuluhan diperlukan suatu metode yang tepat dan disesuaikan dengan kondisi dan situasi serta mendengar masukan dari petani sebagai pihak yang menjadi mitra penyuluh. Dengan kata lain keberhasilan penyuluhan, juga bisa disebabkan oleh metode penyuluhan yang dipergunakan, karena sebaik apapun dan selengkap apapun materi penyuluhan yang disampaikan tidak akan mampu mengubah perilaku sasaran yang diinginkan jika metode penyuluhan yang digunakan kurang tepat. Hal ini sejalan dengan pendapat dari Kang dan Song (Mardikanto, 2009) yang menyimpulkan tentang tidak adanya satupun metode yang selalu efektif untuk diterapkan setiap kegiatan penyuluhan. Kegiatan penyuluhan harus dilaksanakan dengan penerapan beragam metode sekaligus yang saling menunjang dan melengkapi.

Aktivitas evaluasi dalam penelitian ini dilihat dari parameter dilakukan kegiatan evaluasi setelah penyuluhan dilaksanakan dan adanya perbaikan program penyuluhan setelah dilakukan evaluasi. Informan berpendapat bahwa jarang dilakukan kegiatan evaluasi setiap setelah penyuluhan. Bila telah selesai penyuluhan biasanya langsung kembali ke rumah atau tugas masing-masing, sedangkan untuk pertemuan/penyuluhan selanjutnya tidak lagi membahas atau menindaklanjuti materi penyuluhan sebelumnya tetapi berganti dengan materi atau bahan yang lain.

Suatu evaluasi kegiatan sangat diperlukan karena merupakan suatu proses menyediakan informasi yang dapat dijadikan sebagai pertimbangan untuk menentukan harga dan jasa (the worth and merit) dari tujuan yang dicapai, 
desain, implementasi dan dampak untuk membuat keputusan, membantu pertanggungjawaban dan meningkatkan pemahaman terhadap fenomena, dengan kata lain evaluasi adalah penyediaan informasi yang dapat dijadikan sebagai bahan pertimbangan dalam mengambil keputusan (Widoyoko, 2012). Hal ini juga sesuai dengan pendapat Arikunto dan Syafiuddin (2008), bahwa wujud dari evaluasi adalah adanya rekomendasi dari evaluator untuk pengambil keputusan. Hasil FGD dengan anggota kelompok tani secara terperinci dapat dilihat pada Tabel 1

Faktor Yang Berpengaruh Terhadap Peningkatan Kompetensi Kewirausahaan Petani Jagung Adalah: Partisipasi Petani Pada Kelembagaan Sosial Di Masyarakat, Kebijakan Pemerintah Terhadap

\section{Komoditas Jagung.}

Petani yang aktif berpartisipasi di dalam kelembagaan masyarakat maka akan semakin baik kompetensi kewirausahaannya. Hal ini sesuai dengan pendapat Lastinawati (2011) yang menyatakan bahwa tingkat partisipasi petani mempengaruhi kegiatan pembelajaran, pendampingan yang diikuti petani dan kompetensi kewirausahaannya.

Di kelompok tani informan merasa nyaman karena dapat bertemu dan berdiskusi dengan sesama petani yang mereka kenal untuk membicarakan budidaya jagung dan permasalahan yang mereka alami. Selain itu informan merasa dengan mengikuti dan berpartisipasi dalam setiap kegiatan yang dilakukan kelompok dapat memperoleh berbagai informasi baru dan bertukar pengalaman sesama petani maupun dengan pengurus kelompok tani. Malta (2008) menyatakan bahwa partisipasi petani dalam kelompok tani sebagai pusat kegiatan petani akan memudahkan petani untuk mendapatkan informasi.

Informan beranggapan bahwa tugas pemerintah untuk menyediakan sarana dan prasarana usahatani jagung belum berjalan dengan baik. Hal ini dibuktikan dengan sukarnya petani mendapatkan pupuk pada saat dan jumlah yang tepat untuk diberikan pada tanaman jagung. Tidak adanya kepastian harga jual jagung dan tidak terlibatnya pemerintah dalam membantu informan memasarkan jagungnya membuat membuat persepsi yang negatif/pesimis dari petani untuk keterlibatan pemerintah dalam usahatani jagung mereka.

Penentuan harga jual jagung dan membantu pemasaran hasil jagung belum dilakukan pemerintah, serta tidak ikut secara aktif dalam aktivitas jual beli jagung. Selain itu tidak terjaminnya kelancaran subsidi harga dan subsidi input produksi maka telah memberikan nilai yang negatif dari informan terhadap kebijakan pemerintah. Secara terperinci aspek kompetensi dapat dilihat pada Tabel 2 
Aviati dan Endaryanto, KAJIAN PROSES PEMBELAJARAN

Tabel 1. Hasil Focus Group Discussion (FGD) dari Aspek Proses Pembelajaran dalam Penyuluhan Pertanian, Masalah, Usul Perbaikan, Hasil dan Pihak yang Terkait

\begin{tabular}{|c|c|c|c|c|}
\hline $\begin{array}{c}\text { Aspek } \\
\text { Penyuluhan } \\
\text { Pertanian }\end{array}$ & Masalah & Usul Perbaikan & Hasil & Pihak yang terkait \\
\hline $\begin{array}{l}\text { Proses } \\
\text { Pembelajaran } \\
\text { dalam Penyuluhan } \\
\text { Pertanian }\end{array}$ & $\begin{array}{l}\text { - materi penyuluhan } \\
\text { terbatas hanya teknis budidaya } \\
\text { jagung } \\
\text { - perlu adanya materi } \\
\text { tentang akses permodalan, } \\
\text { akses pasar dan peluang- } \\
\text { peluang usaha yang berkaitan } \\
\text { dengan komoditas jagung. } \\
\text { - interaksi petani dengan } \\
\text { penyuluh terbatas pada saat } \\
\text { pertemuan di kelompok } \\
\text { - metode penyuluhan } \\
\text { kurang variatif dan menjadikan } \\
\text { petani aktif } \\
\text { - belum dilakukan } \\
\text { evaluasi penyuluhan dan tidak } \\
\text { lanjut dari suatu penyuuluhan }\end{array}$ & $\begin{array}{l}\text { - adanya upaya pelatihan, } \\
\text { pendidikan dan pendampingan bagi } \\
\text { penyuluh untuk terus meningkatkan } \\
\text { kemampuannya dalam proses } \\
\text { pembelajaran melalui cyber extension. }\end{array}$ & $\begin{array}{l}\text { materi penyuluhan lebih } \\
\text { bervariasi mencakup akses } \\
\text { permodalan, akses pasar dan } \\
\text { peluang-peluang usaha yang } \\
\text { berkaitan dengan komoditas jagung. } \\
\text { - interaksi petani dengan } \\
\text { penyuluh tidak terbatas waktu dan } \\
\text { tempat } \\
\text { - metode penyuluhan sudah } \\
\text { variatif dan menjadikan petani aktif } \\
\text { serta mampu memanfaatkan cyber } \\
\text { extension. } \\
\text { - sudah dilakukan evaluasi } \\
\text { penyuluhan dan adanya tidak lanjut } \\
\text { dari suatu penyuluhan }\end{array}$ & $\begin{array}{l}\text { Penyuluh, Perguruan } \\
\text { Tinggi, MAJ, Stake Holder } \\
\text { lainnya (Penyedia } \\
\text { Saprotan, pihak pabrik } \\
\text { pakan, dan perbankan) }\end{array}$ \\
\hline
\end{tabular}


Tabel 2. Hasil Focus Group Discussion (FGD) dari Aspek Kompetensi Kewirausahaan Petani Jagung, Masalah, Usul Perbaikan, Hasil dan Pihak yang Terkait

\begin{tabular}{|c|c|c|c|c|c|}
\hline No & $\begin{array}{c}\text { Aspek } \\
\text { Penyuluhan } \\
\text { Pertanian }\end{array}$ & Masalah & Usul Perbaikan & Hasil & Pihak yang terkait \\
\hline 1. & $\begin{array}{l}\text { Partisipasi } \\
\text { Petani dalam } \\
\text { Kelembagaan di } \\
\text { Masyarakat }\end{array}$ & $\begin{array}{l}\text { - Keberadaan } \\
\text { kelompok tani ada yang } \\
\text { fiktif atau ada nama } \\
\text { kelompok tapi tidak } \\
\text { ada anggotanya } \\
-\quad \text { tidak aturan main } \\
\text { dalam kelompoktani, } \\
\text { tidak ada sekertariat } \\
\text { kelompok tani }\end{array}$ & $\begin{array}{l}\text { - Adanya rekayasa } \\
\text { kelembagaan kelompok } \\
\text { tani agar kehidupan } \\
\text { organisasi kelompok tani } \\
\text { berjalan dengan aktif } \\
\text { dan dinamis. } \\
-\quad \text { Perlu adanya } \\
\text { pembinaan sekaligus } \\
\text { pendampingan guna } \\
\text { pengaktifan }\end{array}$ & $\begin{array}{l}\text { - Kelompok menjadi suatu } \\
\text { lembaga masyarakat yang kuat, } \\
\text { dinamis dan aktif } \\
\text { - adanya aturan main dalam } \\
\text { kelompok tani, telah ada sekretariat } \\
\text { kelompok tani }\end{array}$ & $\begin{array}{l}\text { Tokoh masyarakat, } \\
\text { pengurus kelompok, dan } \\
\text { penyuluh }\end{array}$ \\
\hline 2. & $\begin{array}{l}\text { Persepsi petani } \\
\text { terhadap } \\
\text { kebijakan } \\
\text { pemerintah }\end{array}$ & $\begin{array}{l}\text { - } \quad \text { Belum ada } \\
\text { kontrak pemasaran } \\
\text { - Pasar melalui } \\
\text { agen/pedagang } \\
\text { perantara (harga murah } \\
\text { dan terlibat praktek } \\
\text { rentenir). } \\
\text { - Belum ada rules of } \\
\text { the games (aturan } \\
\text { main) untuk } \\
\text { pelaksanaan kepastian } \\
\text { harga di tingkat petani } \\
\text { (meski telah ada SK } \\
\text { Gubernur No G/514/ } \\
\text { III.09/ HK/2006 harga } \\
\text { minimal di tingkat } \\
\text { petani jagung }\end{array}$ & $\begin{array}{l}-\quad \text { Adanya bantuan } \\
\text { fasilitasi dan } \\
\text { pendampingan untuk } \\
\text { membantu petani dalam } \\
\text { kontrak pemasaran } \\
\text { - Adanya sosialisasi } \\
\text { dan kejelasan rules of } \\
\text { the games dalam } \\
\text { pelaksanaanan SK } \\
\text { Gubernur No } \\
\text { G/514/III.09/ HK/2006. }\end{array}$ & $\begin{array}{l}\text { - } \quad \text { Adanya kontrak kerja } \\
\text { pemasaran jagung antara petani } \\
\text { dengan pabrik pakan ternak. } \\
-\quad \text { Adanya kepastian harga sesuai } \\
\text { dengan kualitas jagung petani } \\
-\quad \text { Adanya rulesof the games yang } \\
\text { jelas dan tegas sertan sanksi bagi pihak } \\
\text { yang tidak melaksanakan SK Gubernur } \\
\text { No G/514/III.09/ HK/2006. }\end{array}$ & $\begin{array}{l}\text { Pemerintah Daerah, Pabrik } \\
\text { pakan ternak, MAJ, } \\
\text { Kelompok Tani/Gapoktan. }\end{array}$ \\
\hline
\end{tabular}




\section{KESIMPULAN DAN SARAN}

\section{KESIMPULAN}

Berdasarkan analisis dan pembahasan terhadap data penelitian maka dapat disimpulkan bahwa:

(1) Aspek dalam proses pembelajaran dalam penyuluhan yang memberikan dampak terhadap kompetensi kewirausahaan petani jagung di Kabupaten Grobogan yaitu materi penyuluhan, interaksi antara penyuluh dan petani, metode, dan evaluasi penyuluhan.

(2) Faktor yang berpengaruh terhadap peningkatan kompetensi kewirausahaan petani jagung adalah: partisipasi petani pada kelembagaan sosial di masyarakat dan kebijakan pemerintah terhadap komoditasjagung.

\section{SARAN}

Berdasarkan temuan implikasi hasil penelitian maka disarankan beberapa hal sebagai berikut:

\section{(1) Bagi Penyuluh Pertanian}

(a) Perlu perubahan paradigma proses pembelajaran dalam penyuluhan yang 'hanya' menjalankan tugas/kewajiban untuk menyampaikan program yang telah ditetapkan pemerintah kepada proses penyuluhan untuk merubah mind set petani dari 'perilaku' penerima subsidi dan penerima bantuan menjadi perilaku seorang wirausaha.

(b) Perlu adanya pemanfaatan terkait teknologi informasi untuk melaksanakan penyuluhan agar dapat dengan cepat menyampaikan informasi kepada petani.

\section{(2) Pemerintah Daerah}

(a) Pemeritah harus menjamin ketersediaan saprotan dalam jumlah yang mencukupi dan pada waktu yang tepat bagi pemenuhan kebutuhan usahatani petani.

(b) Program penyuluhan yangdibuat lebih diarahkan kepada cyber extension dengan menambah perangkat teknologi informasi di setiap Balai Penyuluhan

\section{DAFTAR PUSTAKA}

Ahmad, N.H. 2007. A Cross Cultural Study of Entrepreneurial Competencies and Entrepreneurial Success in SMEs in Australia and Malaysia. Adelide Business School. Adelaide. University

Asngari, P.S., .2001. Peran Agen Pembaruan/Penyuluh dalam Usaha Memberdayakan (Empowerment) Sumberdaya Manusia Pengelola Agribisnis. Orasi Ilmiah Guru Besar Tetap Ilmu Sosial Ekonomi. Fakultas Peternakan. Institut Pertanian Bogor. 15 September 2001.

Chandler, G. N. dan Hanks, S.H. 1994. Founder Competence, The Environment, and Venture Performance. Entrepreneurship Theory and Practice. 18 (3): 77-89.

Departemen Pertanian. 2007. Peraturan Menteri Pertanian RI No. 273/KPTS/OT.160/4/2007.Jakarta: Deptan

Evers, F. T., James C., Iris Berdrow. 1998. The Bases of Competence: Skills for Lifelong Learning and Employability. San Fansisco: Jossey-Bass Publishers.

Hoffman, T. 1999. The Meaning of Competency. Journal of European Industrial Training. 23: 275-285.

Husamah dan Yanuar Setyaningrum. 2013. Desain Pembelajaran Berbasis 
Pencapaian Kompetensi. Jakarta: Prestasi Pustaka.

Ibrahim, J. T., A. Sudiyono dan Harpowo. 2003. Komunikasi dan Penyuluhan Pertanian. Malang: Bayu Media Publishing.

Khudson, W., Wysocki, A., Champagne, J., and Peterson, H. C. (2004). Entrepreneurship and innovation in the agri-food system. The American Journal of Agricultural Economics, 86(5), 13301336.

Lastinawati, E., 2011. Partisipasi Petani dalam Pelaksanaan Program Pengembangan Usaha Agribisnis Pedesaan (PUAP) di Kab. OKU. AgronobiS, Vol. 3 No. 5, Maret 2011., Hal: 47-57

Malta. 2011. Faktor-Faktor yang Berhubungan dengan Kinerja Petani Jagung di Lahan Gambut. Mimbar. Vol. XXVII. No. 1. (Juni 2011): 67-78.

Man, T.W.Y., Lau and K.F. Chan, 2002. The Competitiveness of Small and Medium Enterprises - A Conceptualization with Focus on Entrepreneurial Competencies. Journal of Business Venturing 17: 123142.

Mangkuprawira, S. 2004. "Arti dan Beragam Aspek tentang Kompetensi". Makalah Penunjang untuk lokakarya Fakultas Pertanian. Institut Pertanian Bogor. 28 April 2004. Bogor.

Mardikanto, T 2013. Sistem Penyuluhan Pertanian. Pusat Pengembangan Agrobisnis dan Perhutanan Sosial. Cetakan 3. Surakarta: Sebelas Maret University Press.

Mardikanto, T. 2009. Sistem Penyuluhan Pertanian. Pusat Pengembangan Agrobisnis dan Perhutanan Sosial. Cetakan 1. Surakarta: Sebelas Maret University Press.

Mustofa, J. 2011. Peningkatan Kompetensi Guru Melalui Pelatihan dan Sumber Belajar Teori dan Praktik. Jakarta: Kencana Prenada Media Group.

Rowe, C. 1995. Clariying The Use of Competence and Competency Models in Recruitment, Assessment and Staff
Development. Industrial and Commercial Training, 27: 12-17.

Slamet, M. 2001. Paradigma Baru Penyuluh Pertanian di Era Otonomi Daerah. Makalah disampaikan pada Seminar PERHIPTANI di Tasikmalaya. Jawa Barat. Tanggal 21 Oktober 2001.

Slamet, M. 2003 Memantapkan Penyuluhan Pertanian di Indonesia Dalam Membentuk Pola Perilaku Manusia Pembangunan. Diedit oleh adjat Sudrajat dan Ida Yustina. Bogor: IPB Press. Hal. 15-45

Sudjana, N. dan Ibrahim. 2003. Penelitian dan Penilaian Pendidikan. Bandung: Sinar Baru.

Sumardjo. 2012. "Omong Kosong, Pertanian Tanpa Penyuluhan". Tabloid Sinar Tani, Edisi 3-9 Oktober 2012 No 3476 Tahun XLIII. Hal: 4.

Suryana, Y. dan Kartib B. 2010. Kewirausahaan: Pedoman Praktis, Kiat dan Proses Menuju Sukses. Jakarta: Salemba Empat

Syafiuddin. 2008. Hubungan Karakteristik Dengan Kompetensi Pembudidaya Rumput Laut (Euchema spp.) Di Tiga Kabupaten Di Provinsi Sulawesi Selatan. Disertasi. Sekolah

Vesala, K.M. dan Pyysiainen, J. 2008. Understanding Entrepreneurial Skills in the Farm Context. Final Report on the Main Study of the EU-funded Project. Research Institute of Organic Agriculture. Frick, Switzerland: P. 1-67.

Wiriaatmadja, S. 1990. Pokok-Pokok Penyuluhan Pertanian. Jakarta: Yasaguna. 